\title{
State of Public Health of Refuge Children Due to the Syrian War: A Narrative Review
}

\author{
Teymouri. $\mathrm{F}^{1}$ \\ *Dabbagh Moghaddam. A $^{2}$ \\ 1- Ph.D. Student of Health in \\ Emergencies and Disasters, \\ Instructor, Psychiatric Nursing \\ Department, Faculty of Nursing, \\ Aja University of Medical \\ Sciences, Tehran, Iran. \\ 2- $\left({ }^{*}\right.$ Corresponding Author) \\ $P h D$ in Food Sciences and \\ Hygienic, Assistant Professor, \\ Aja University of Medical \\ Sciences, Tehran, Iran. \\ Email:dr.arasb@gmail.com
}

\begin{abstract}
Introduction: The Syrian war has many humanitarian consequences for the refugees. Children in the plight of war face many health challenges due to their vulnerability to other age groups. This study aimed to investigate and analyze the public health of refugee children caused by the Syrian war.

Materials and Methods: In this Review study, an extensive search was conducted using the terms, "War", "Syria", "Crisis", "Violence", "child", "Refuge” and "Public Health" (from PubMed, ProQuest, Sid, Google, Google Scholar, Scopus, Iran Medex, Web of Science Cinhaland WHO, UNHCR, UNICEF, OCHA databases in Farsi and English) from 2011 to 2019. The literature was independently reviewed by two authors.
\end{abstract}

Results: A total of 8 articles out of 75 articles consistent with the purpose of the study were evaluated based on inclusion and exclusion criteria and repeated studies. The results of the study showed that the unrest in the country, poor living conditions, inaccessibility to safe food and water, the collapse of health care centers and inadequate vaccination coverage have caused many infectious diseases, such as polio and measles, increased malnutrition and anemia

Discussion and Conclusion: Refugees' children are in poor health for various reasons. Considering the vulnerability of children at war, and the high number of refugees from this age group, prevention, preparedness and response programs based on children's needs should be designed and monitored by governments and humanitarian organizations.

Keywords: Child, Public Health War, Refuge, Syria. 


\title{
وضعيت بهداشت عمومى كودكان آواره ناشى از جنك سوريه: يك مرور روايتى
}

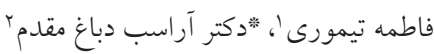

جكيده

مقدمه: جنگ سوريه تبعات انسانى فراوانى را از حيث آواره شدن جمعيت اين كشور برجاى كذاشته است. در شرايط

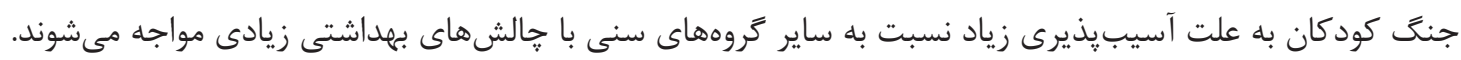

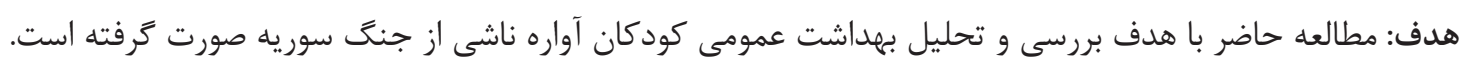

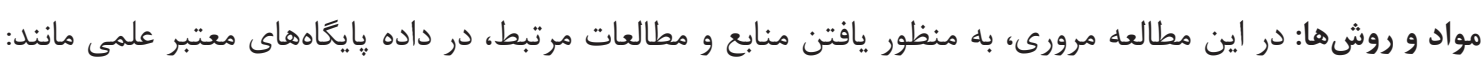
PubMed, ProQuest, Sid, google, google Scholar, Scopus, Iran medex, Web of Science Cinhal WHO, UNHCR, UNICEF, OCHA

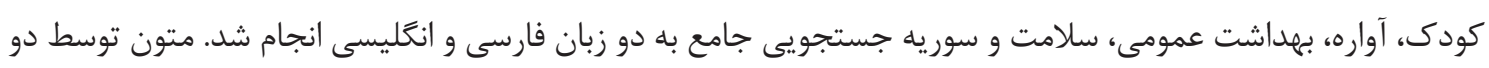

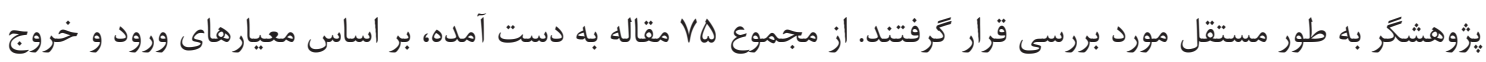

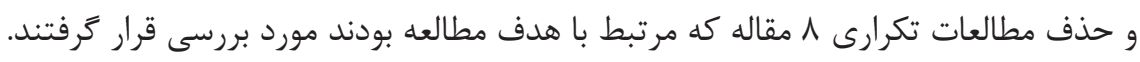

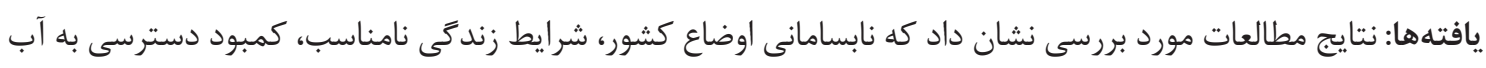

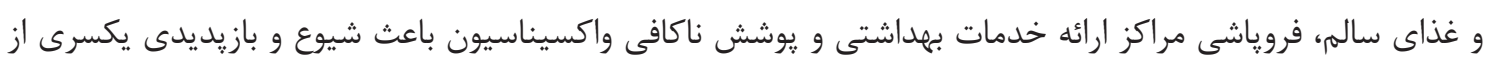

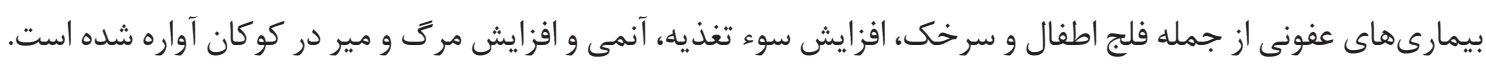

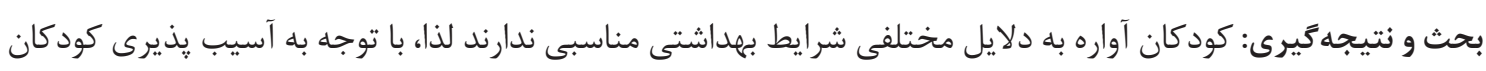

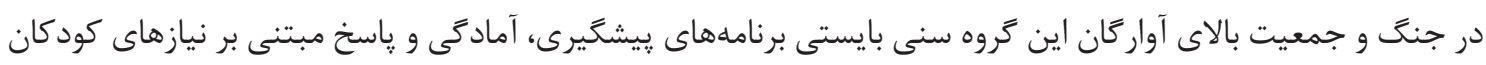
طراحى و تحت توجه دولتها و سازمانهاى بشردوستانه قرار كيرد.

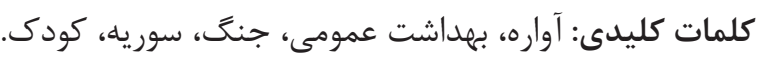

\begin{tabular}{|c|c|c|}
\hline $1 \mu q \Lambda / \mathrm{N} / \mu$ & 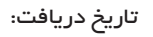 & 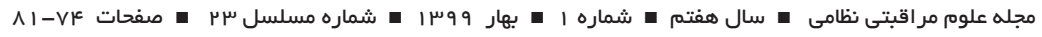 \\
\hline 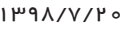 & تاريخ يذيرش: & \\
\hline । $\mu q 9 / \mu / \mu \Delta$ & تاريخ انتشار: & \\
\hline
\end{tabular}

شد لذا، رسالت و وظيفه اصلى بهداشت عمومى، استقرار تندرستى مقلممه

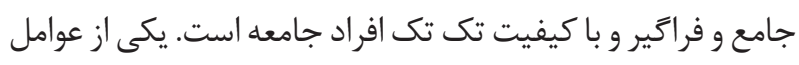
مؤثر بر بهداشت عمومى، شرايط و مقتضيات كوناكونى است كه ونه

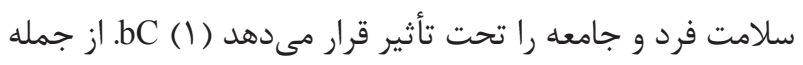

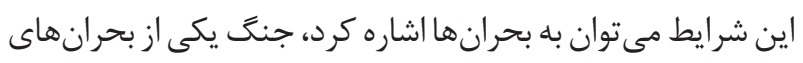

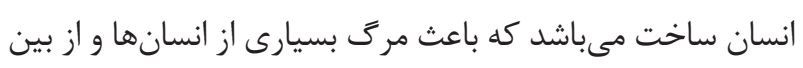

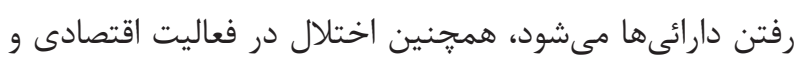

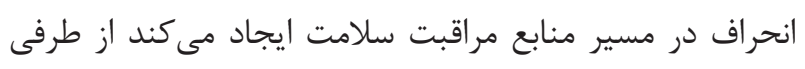
بهداشت و سلامت يكى از اركان اساسى در نظام حقوق بشر است

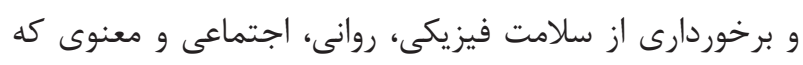

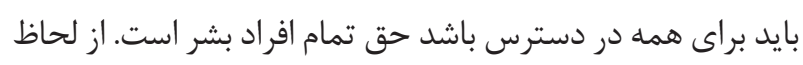

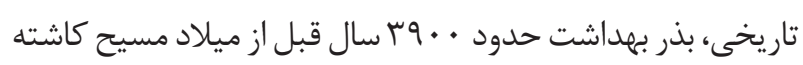
شد و در سال ؤ 19 ميلادى به عالىترين ثمره خود كه تصويب اساسنامه سازمان جهانى بهداشت بود دست يافت و بدين وسيله هدف نهايى بهداشت، تأمين، حفظ و ارتقاى سلامت بشرى اعلام بهان 
كه از علل افزايش ميزان ابتلا و مرك و مير كودكان بود (سا) ). از

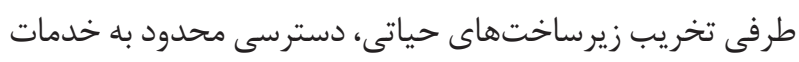

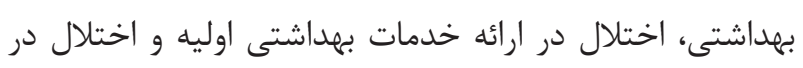

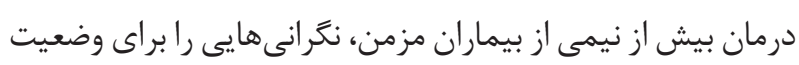

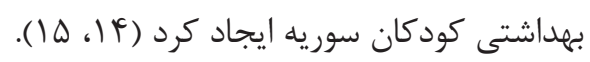

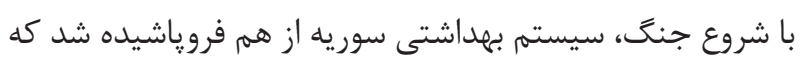

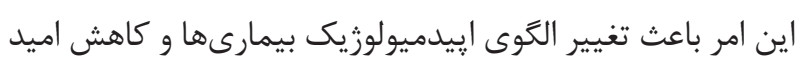

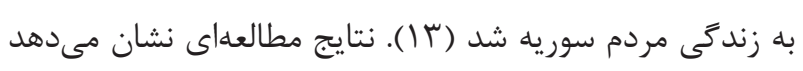

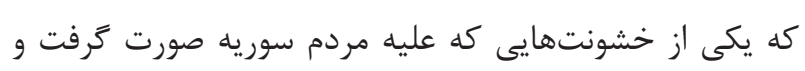

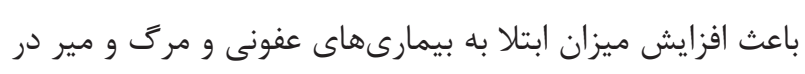
كود كان شد، تعداد زياد حملاتى است كه مراكز بهداشتى سوريه

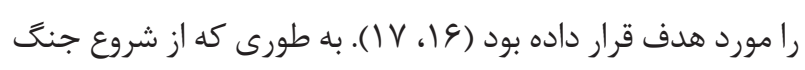

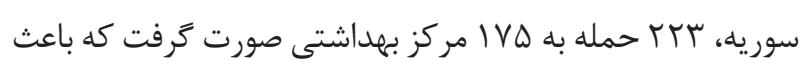

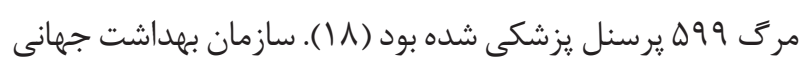

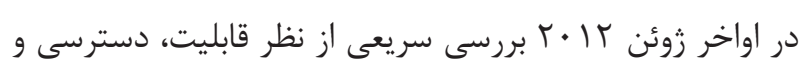

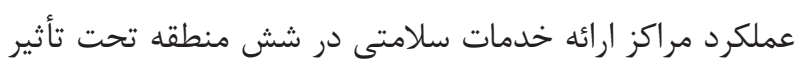

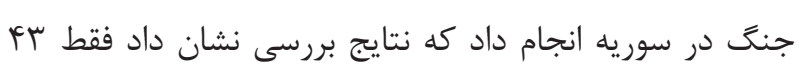

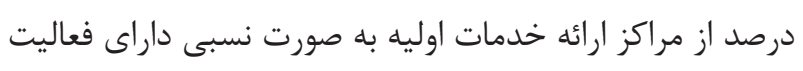

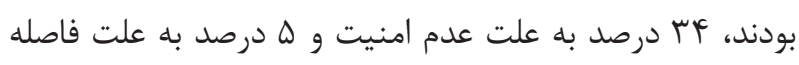

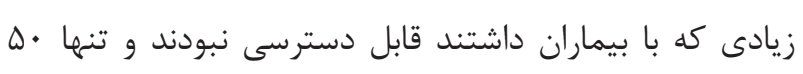

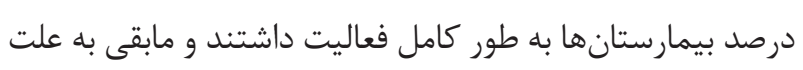
كمبود يرسنل، تجهيزات و دارو قابليت ارائه خدمات نداشتند

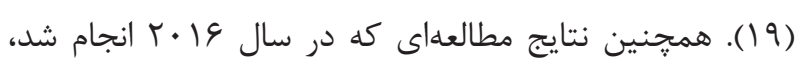

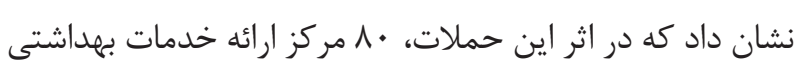

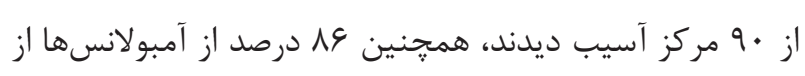

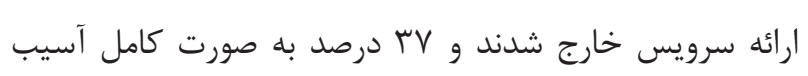
ديدند (·r). طبق كزارش يونيسف يوشش واكسيناسيون كودكان

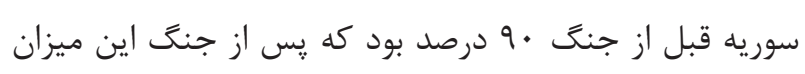

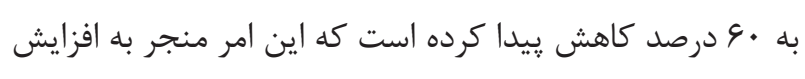

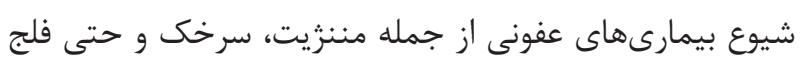

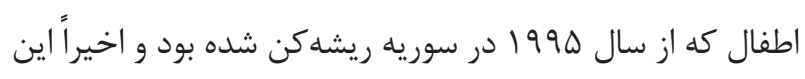
بيمارى به عنوان بيمارى بازيديد شيوع پيدا كرده است (• (1).

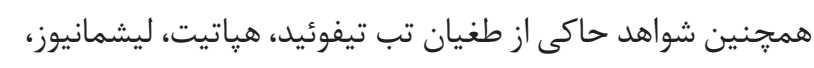

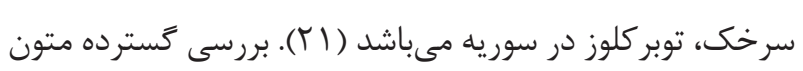

آواركان زيادى را به سمت مناطق يرجمعيت، بدون دسترسى به

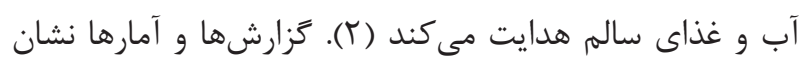

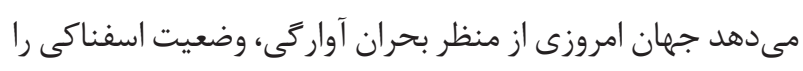

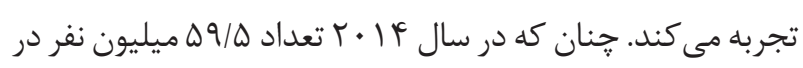
جهان مجبور به ترك خانهاى خود شدند و اين ميزان براى سال

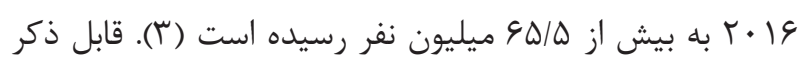

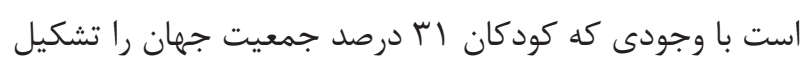
مى دهند اما اله درصد از كل جمعيتى كه آواره مىشوند، كودكان

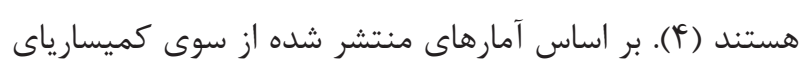

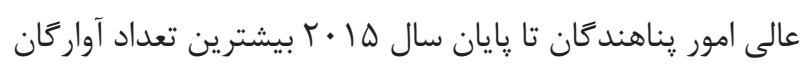
مربوط به كشورهاى سوريه، افغانستان، سومالى و سودان بودهاند

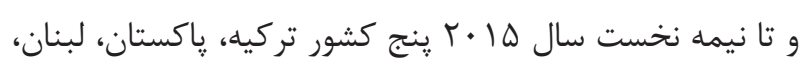

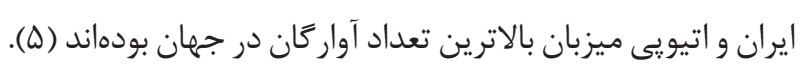
جنَ اثرات مستقيمى بر شرايط جسمى، روانى و اجتماعى آواركان

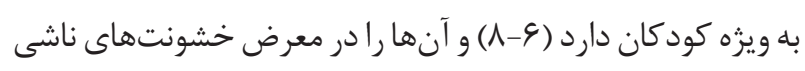

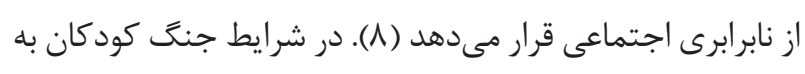

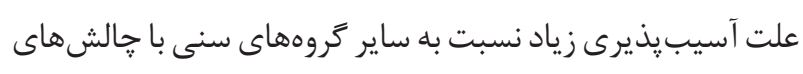

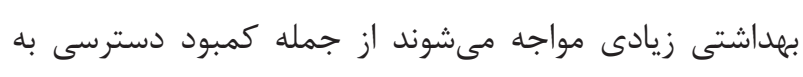
خدمات سلامتى، يوشش ناكافى واكسيناسيون، خطر سوء تغذيه و

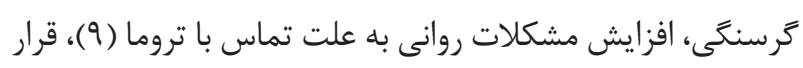
كرفتن در معرض استثمار از جمله ازدواج زودهنغام و سوءاستفاديه

و خشونت مبتنى بر جنسيت را معتوان نام برد (• (1) 11).

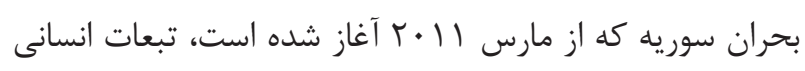

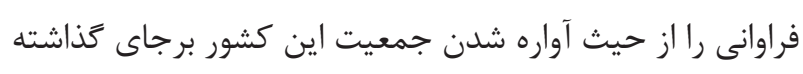

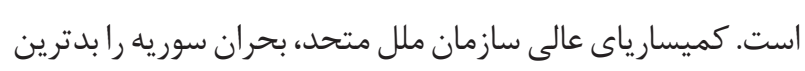

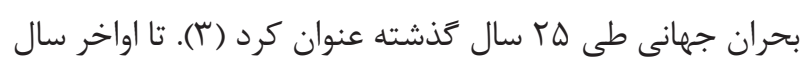

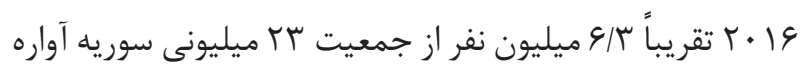

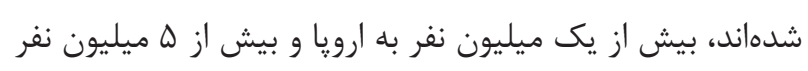

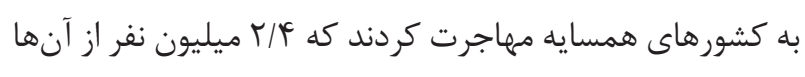
را كودكان تشكيل مىدهند (ب (I). در جنى سوريه تخريب زيرساختها و افزايش شيوع ناقلين،

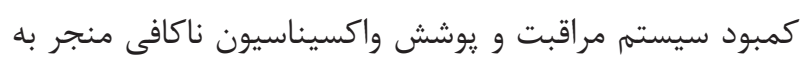

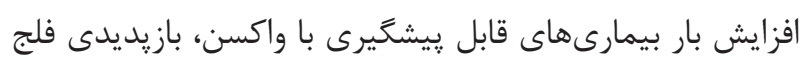

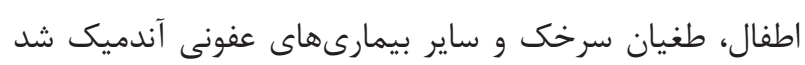




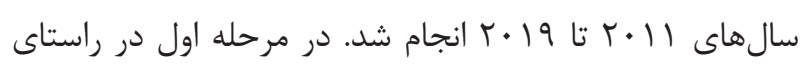

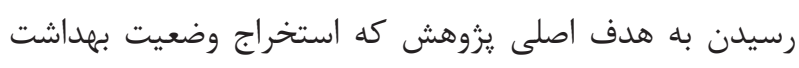

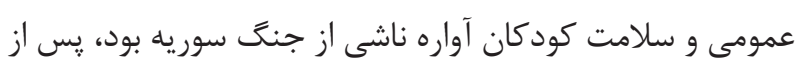

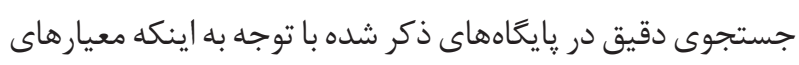

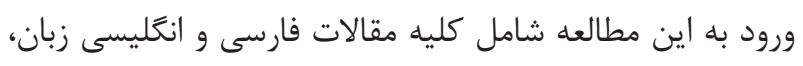

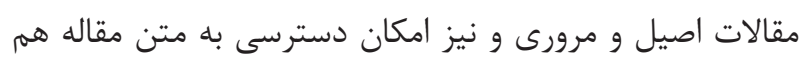

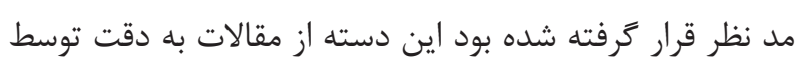

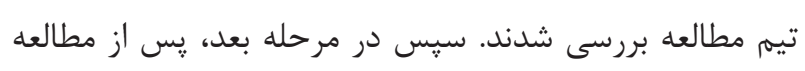

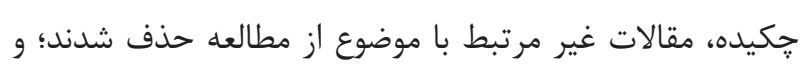
در نهايت پِ از حذف مقالات تكرارى و هميوشان تيم تحقيق به مقاله

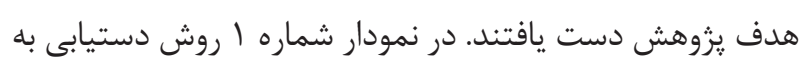

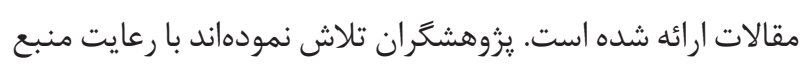

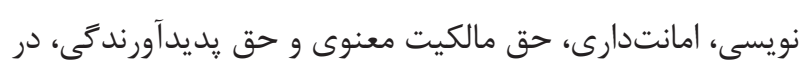
انتقال دادههاى مطالعات مورد استفاده، ارائه صادقانهاى از نتايج ماندي داشته باشد.

يافتهها از مجموع له مقاله در مرحله اول كه با كليد وازكان ذكر شده
نشان مى دهد كه اكثر مطالعات، وضعيت بهداشت عمومى كودكان

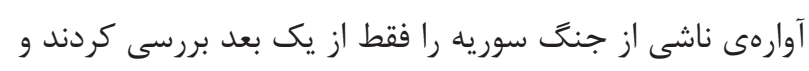

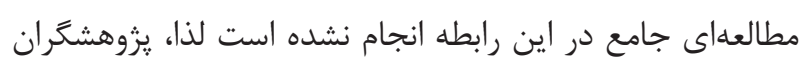

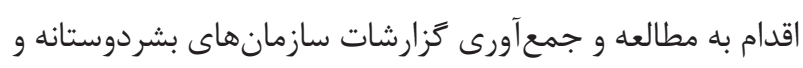

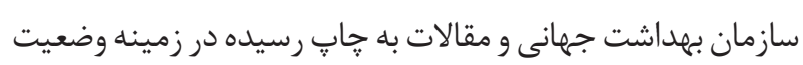

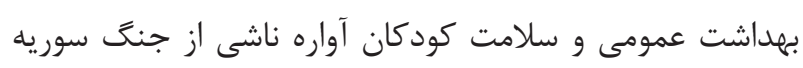

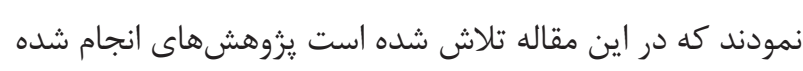
در اين خصوص سازماندهى و جمعبندى گر دد.

\section{مواد و روشها}

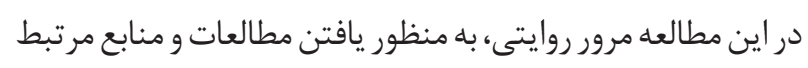

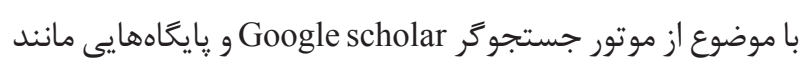
Cinhal, PubMed, ProQuest, Sid, google, google Scholar, WHO, و سايتهاى Scopus, Iran medex, Web of Science UNHCR,UNICEF, OCHA مقالات با استفاده از كلمات كليدى جنَ (War)، بحران (Crisis)،

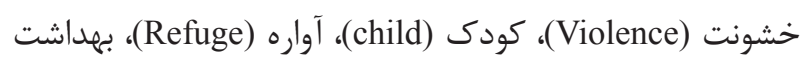

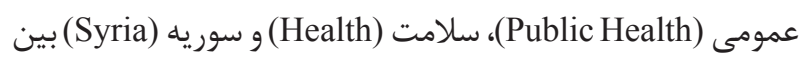

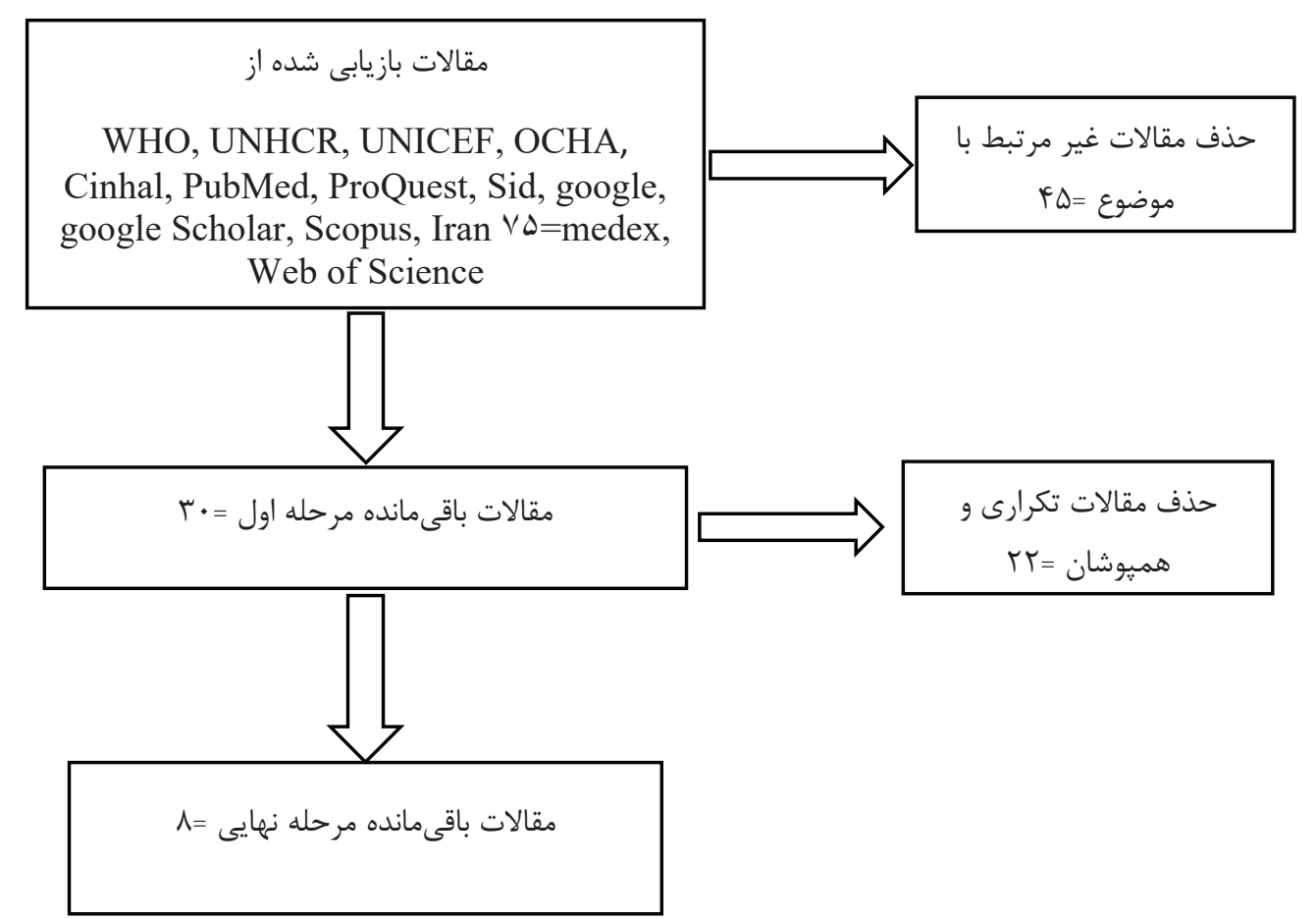

نمودار ا - فلوجارت جستجو و انتخاب مقالات 
بودند. نتايج مطالعات مورد بررسى حاكى از آن بودند كه جنگ

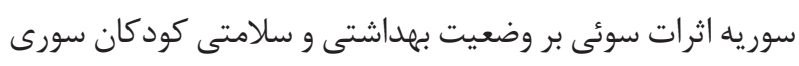

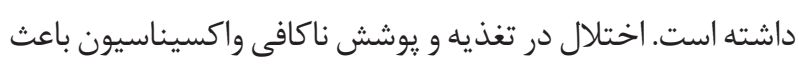

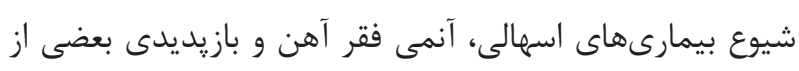

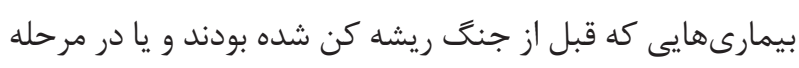

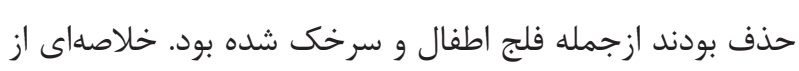

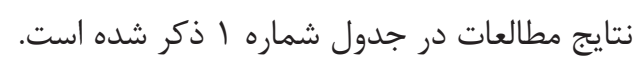

در هايعاههاى ياد شده به دست آمدند، با توجه به اينكه در اين

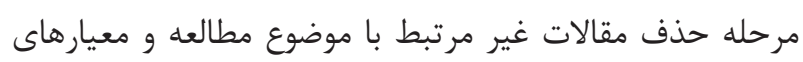

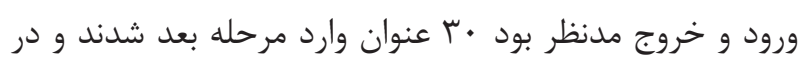

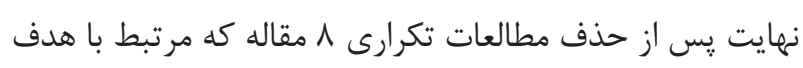

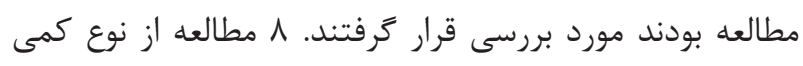

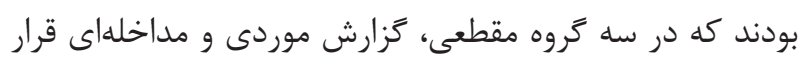

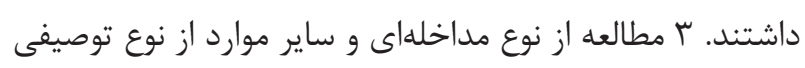

جدول ا- مطالعات منتشر شده در خصوص وضعيت بهداشت عمومى كودكان آواره ناشى از جنَى سوريه

\begin{tabular}{|c|c|c|c|c|c|}
\hline نتايج كلى & مطالعه & سال & عنوان مطالعه & نويسندًَان & رديف \\
\hline 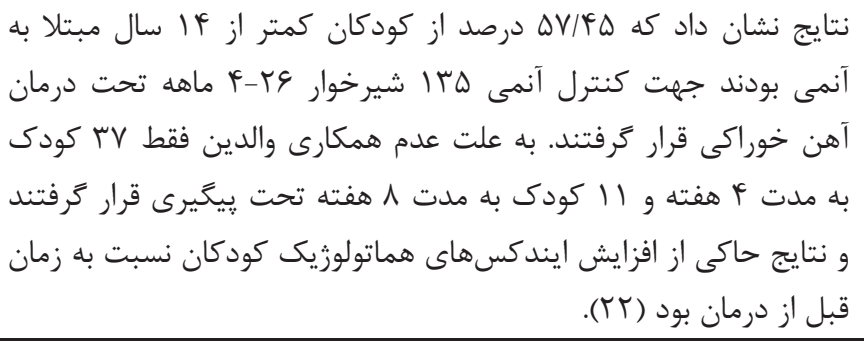 & 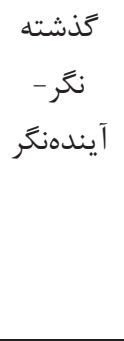 & .19 & شقر آهن و آنمى فتيص و كنتر آهن & $\begin{array}{c}\text { (آلبارودى } \\
\text { (Albaraudi) } \\
\text { همكاران }\end{array}$ & 1 \\
\hline 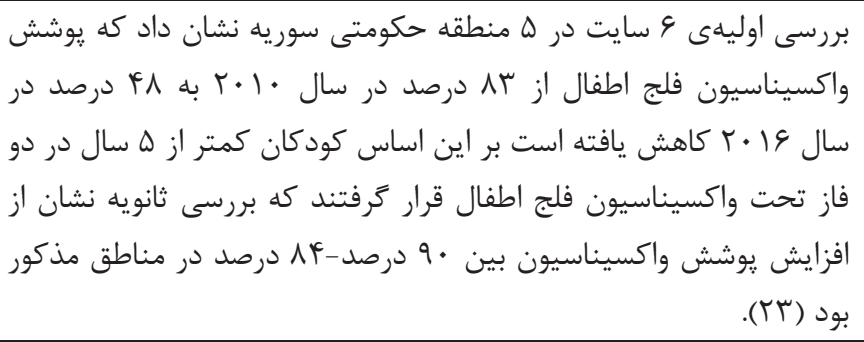 & مزارش & $r \cdot 11$ & 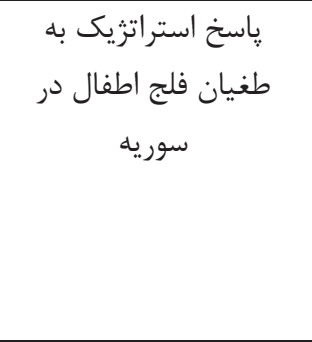 & 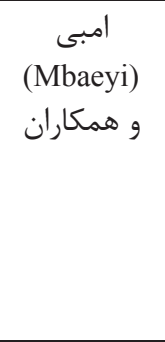 & $r$ \\
\hline 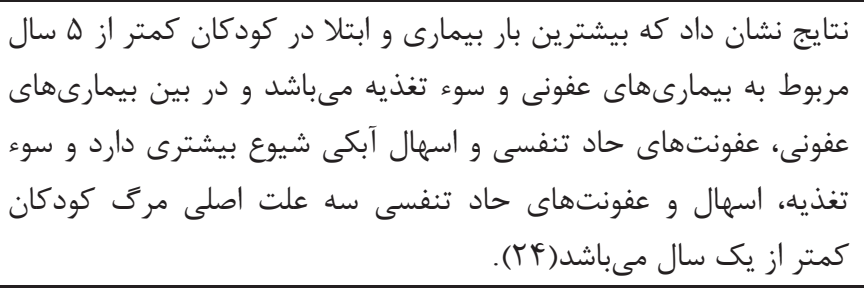 & مقطعى & $r \cdot 11$ & 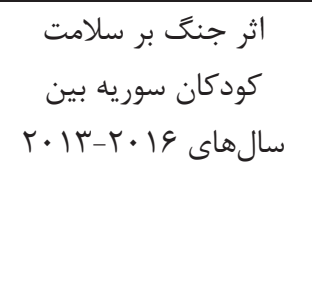 & 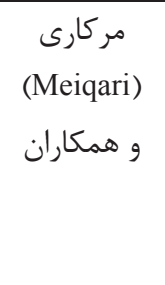 & $r$ \\
\hline 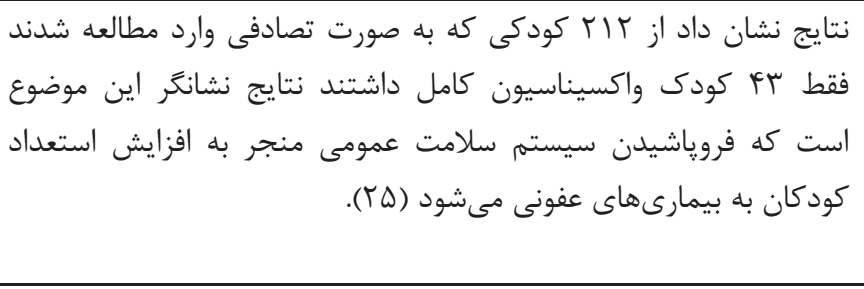 & توصيفى & $r \cdot 11$ & 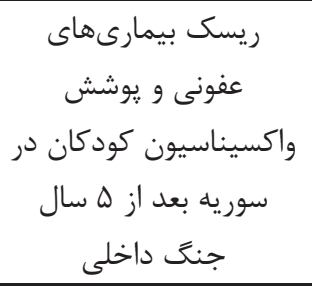 & $\begin{array}{c}\text { دليما } \\
\text { و همكاران (De Lima) }\end{array}$ & r \\
\hline 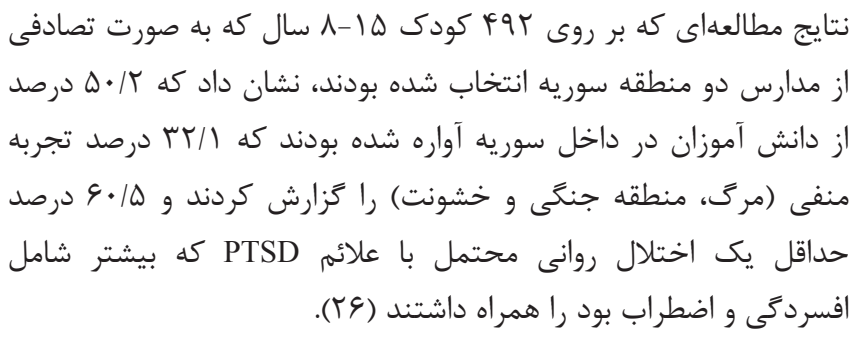 & مقطعى & $r \cdot 11$ & 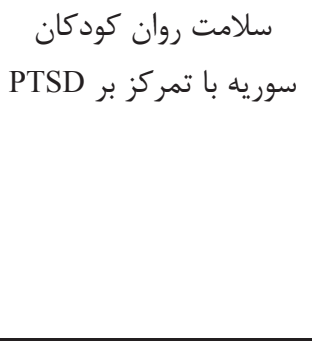 & $\begin{array}{l}\text { و هيركينز } \\
\text { (Perkins) }\end{array}$ & $\Delta$ \\
\hline
\end{tabular}


ادامه جدول ا

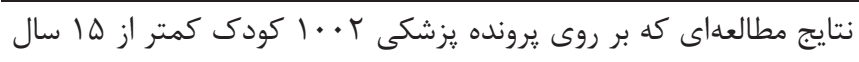

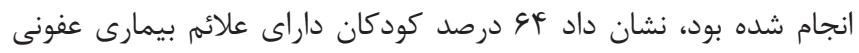

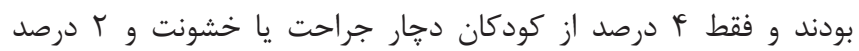
داراى اختلالات روانى بودند (TV)

\begin{tabular}{|c|c|c|c|c|}
\hline مقطعى & $T \cdot I V$ & سراحات در كودكان عفونتها و & $\begin{array}{c}\text { وان برلر } \\
\text { و همكاران } \\
\text { (berlaer) }\end{array}$ & 9 \\
\hline
\end{tabular}

\begin{tabular}{|c|c|c|c|}
\hline كذشت - كَش & $r \cdot I V$ & 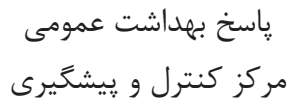 & $\begin{array}{c}\text { بويد } \\
\text { (Boyd) }\end{array}$ \\
\hline نغر & & از بيمارىها به & اران \\
\hline
\end{tabular}

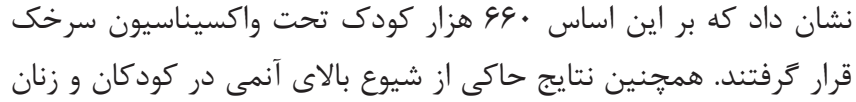

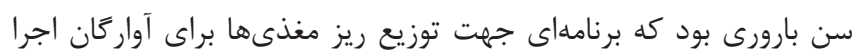

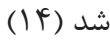

تداوم جنگ و تحريم اقتصادى، ظرفيت خدمات بهداشتى را در معرض

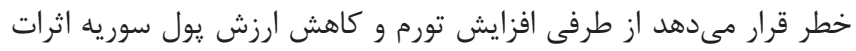

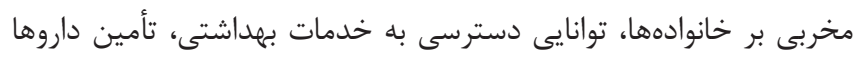

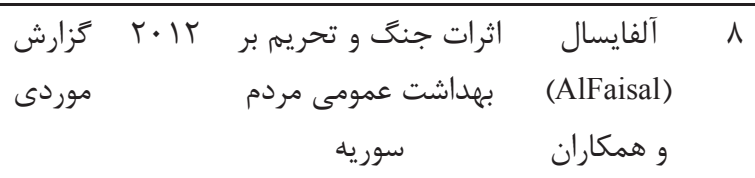

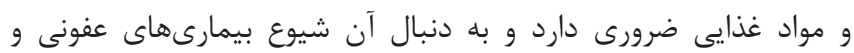

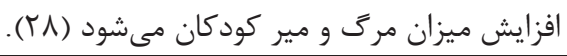

اختلال در دسترسى به واكسيناسيون روتين و يوشش ناكافى بحث و نتيجه كيرى واكسيناسيون مىباشد، به طورى كه نتايج مطالعه دليما يريرا و همكاران نشان داد از rا ب كودكى كه به (De Lima Pereira) صورت تصادفى تحت مطالعه قرار گرفته بودند، فقط س بودى كو واكسيناسيون كامل داشتند كه اين امر باعث گزارش مواردى از سرخك، فلج اطفال، تيفوئيد و هياتيت A شده بود (ه). نتايج مطالعهى ديخرى در ه منطقه حكومتى سوريه نيز نشان داد كه يوشش واكسيناسيون فلج اطفال از rم درصد در سال • • •

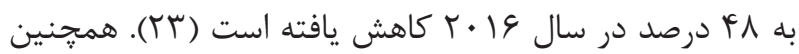
نتايج مطالعه بويد (Boyd) و همكاران f أ سال بعد از شروع جنَ سوريه، كاهش يوشش واكسيناسيون سرخك در كودكان از ج

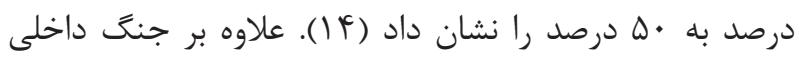
كه مردم سوريه از آن رنج مىبردند و وضعيت بهداشتى كشور را مورد تهديد قرار داده بود، تحريم اقتصادى سوريه نيز تأثيرات مضاعفى رابر سلامتى و وضعيت بهداشتى كود كان ايجاد كرده بود. به طورى كه تحريم باعث اختلال در تأمين انرزى براى جندين ساعت در طول روز در بسيارى از مناطق سوريه شده بود كه اين شرايط باعث شد افراد آسيب يذير بهويزه كودكان در معرض كرما و سرماى شديد قرار زيرند همجنين بلهواسطه آسيبى كه
مطالعه حاضر با هدف بررسى وضعيت بهداشت عمومى كودكان آواره ناشى از جنَ سوريه انجام شد. بررسى و مقايسه مطالعات مختلف بررسى شده در اين مقاله در خصوص وضعيت بهداشت عمومى و سلامت كودكان آواره ناشى از جنَ سوريه نشان مىدهد كه كودكان بيشتر از ساير زروههاى آسيب پذير تحت

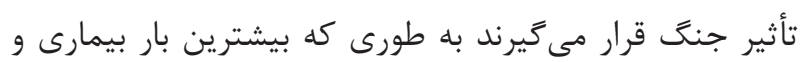
مرگ در كودكان كمتر از ه سال مربوط به بيمارىهاى عفونى مىباشد. شرايط زندگى نامناسب، كاهش دسترسى به آب و غذاى سالم از عواملى است كه بر وضعيت بهداشتى كودكان و شيوع بيمارىهاى عفونى در زمان جنَ تأثير مى گذارد (YY). وان برلر (Van Berlaer) و همكاران مطالعهاى مقطعى با هدف تشخيص عفونتها و جراحات در كودكان سوريهاى، أ سال بعد از شروع جنَ انجام دادند نتايج نشان داد، أو درصد كودكان كه ·• درصد از آنان كمتر از ه سال سن داشتند داراى علائم بيمارى عفونى بودند كه بيشتر داراى منشأ تنفسى مثل ينومونى

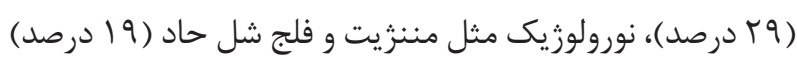
و گوارشى مثل اسمال خونى و آبكى (YV) د IV) (YV). يكى از مهمترين علل طغيان بيمارىهاى عفونى در بحرانها، 
نشان مى دهد كه عواملى همجون تعاملات مثبت با (Gartland)

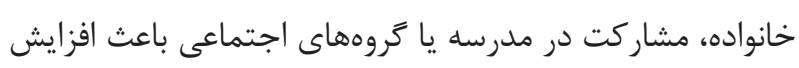

تاب آورى كودكان در حوادث و بلايا مىشود (9 ؟).

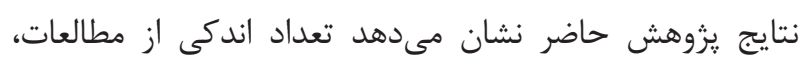

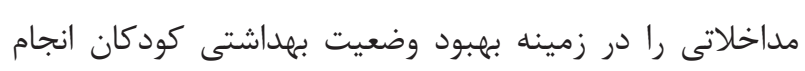

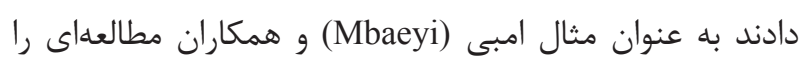
با هدف پاسخ استراتزيك به طغيان فلج اطفال در سوريه سال

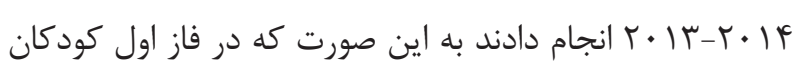
كمتر از ه سال تحت واكسيناسيون غير فعال فلج اطفال قرار

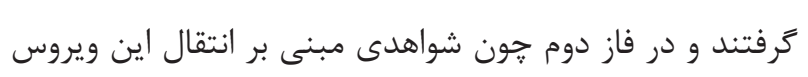

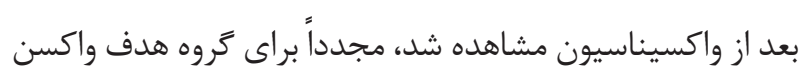

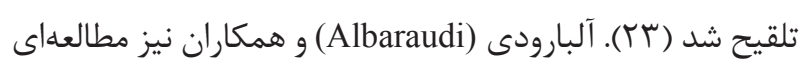

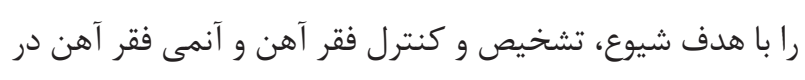

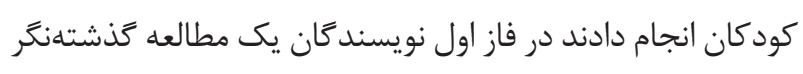
بر روى ايندكسهاى هماتولوزيك از نظر شمارش كَلبولهاى داى دان

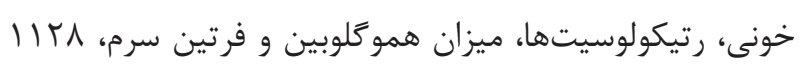

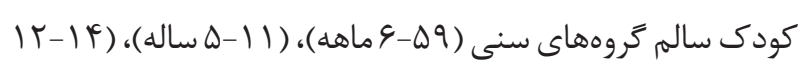

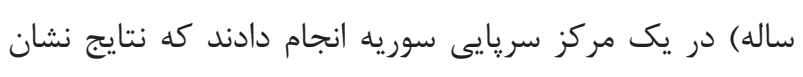

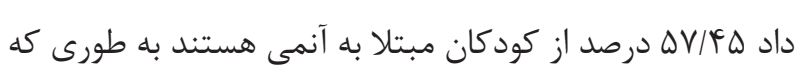

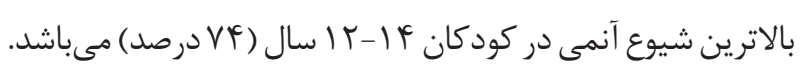

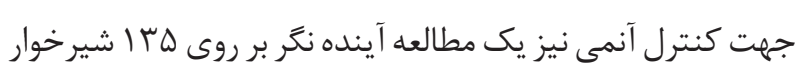

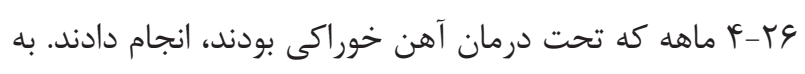

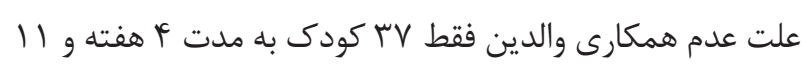

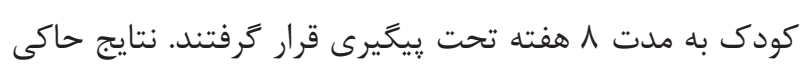

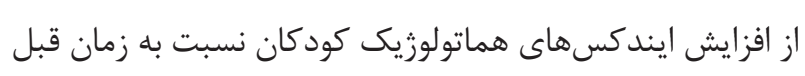

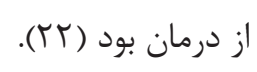

اميد است نتايج مطالعات مورد بررسى در يروهش حاض برد (بر).

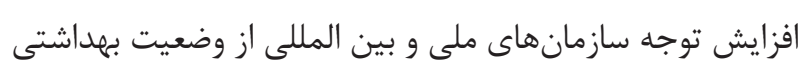

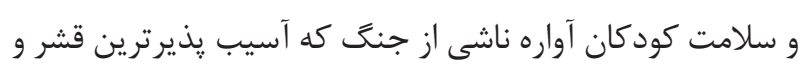
آينده سازان جامعه هستند، شود و تا حدى در شناسايى نيازهاى

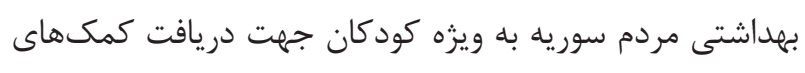
بشردوستانه كمك كننده باشد. از محدوديتهاى اين يروهش برد برد

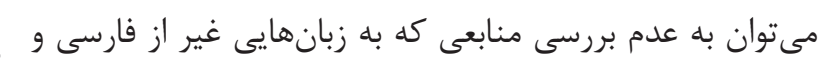
انغليسى جاب شده بودند، اشاره كرد.
به زنجيره سرماى واكسنها وارد كرد اين احتمال وارد است كه يكى از علل شيوع بيمارىهاى عفونى در كودكان باشد. از طرفى ونى

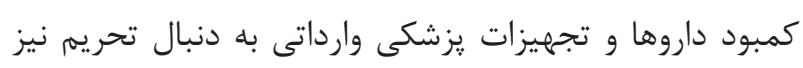

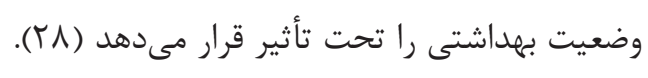

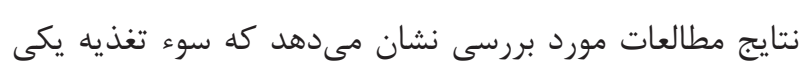

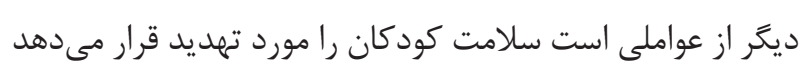

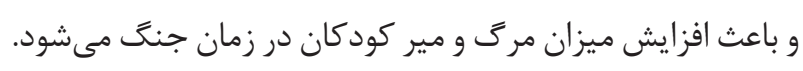

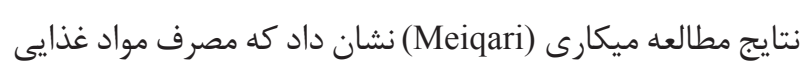

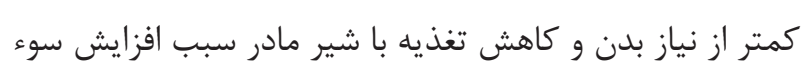
تغذيه و ميزان مرى و مير بهويزه در كودكان كمتر از يك سال

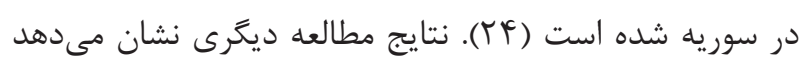
مشكلات تغذيهاى كه كودكان به علت شرايط نابسامان كشور با آن مواجه بودند باعث افزايش شيوع آنمى فقر آهن نيز شده بـ ندابه

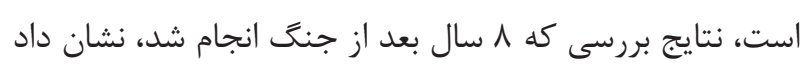

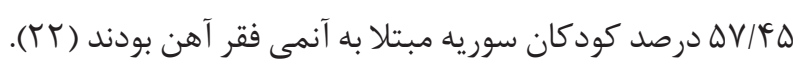

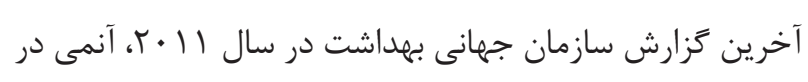

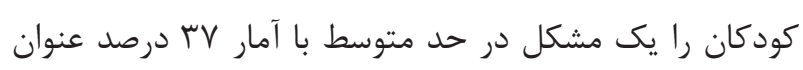

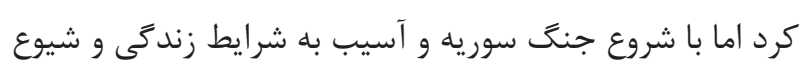
سوءتغذيه در كودكان، ميزان شيوع آنمى در كودكان سوريه در

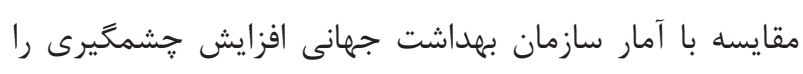

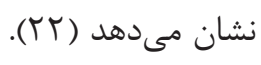
در مطالعات مورد بررسى وضعيت بهداشتى كودكان را از منظر

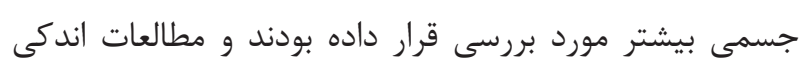

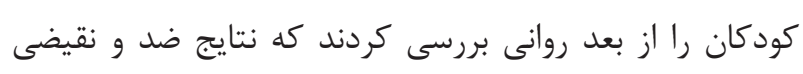
داشتند از جمله نتايج مطالعه يركينز (Perkins) و همكاران نشان رونان

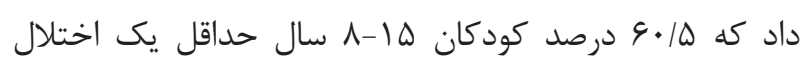
روانى كه بيشتر شامل، PTSD، افسردگى و اضطراب بود ران راه همراه

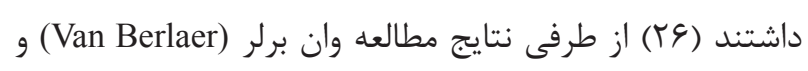

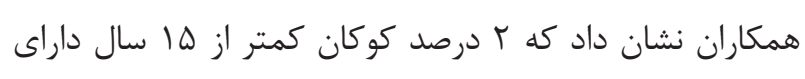

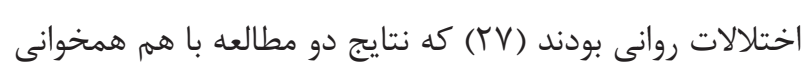
نداشتند. علت عدم همخوانى ممكن است مرتبط با استرسورهاى روناي

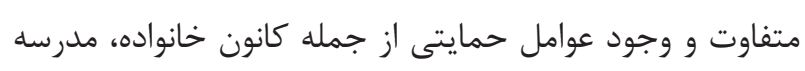

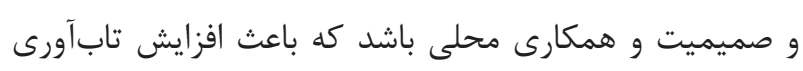
كود كان در برابر ديسترس هاى روانى مى ودود. نتايج مطالعه كار تلند 


$$
\text { تضاد منافع بن منافع در خصوص يزوهش حاضر وجود ندارد. }
$$

\section{References}

1- Abasi MD, Rezai R. The Legal Requirements of International Documents on Public Health and Challenges of it faces. J Med Counc IR Iran. 2015;2(33):138-46.

2- Ghobarah HA, Huth P, Russett B. The post-war public health effects of civil conflict. Soc Sci Med. 2004;59(4):869-84. http:// dx.doi.org/10.1016/j.socscimed.2003.11.043 www.ncbi.nlm.nih. gov/pubmed/15177842

3- Zarghani HA. Analysis of the regional and global consequences of the Syrian geopolitical crisis with emphasis on the refugee crisis. Geography. 2018(57).

4- Denov M, C. Shevell M. Social work practice with war-affected children and families: the importance of family, culture, arts, and participatory approaches. J Family Social Work. 2018;22(1):1-16. http://dx.doi.org/10.1080/10522158.2019.1546809

5- Jahangiri K. View of Mental and Social Health of Refugee Women in the Third Millennium: The big National and International Challenge. nian J Health Educat \& Health Promotion. 2018;06(02):134-46. http://dx.doi.org/10.30699/acadpub. ijhehp.6.2.134

6- Simsek BK. War surgery in a Turkish hospital near the border of Syria: An evaluation in terms of critical and intensive care treatment principles. Turkish J Trauma \& Emergency Surgery. 2016. http://dx.doi.org/10.5505/tjtes.2016.95525

7- Lutz C, Mazzarino A. War and Health: The Medical Consequences of the Wars in Iraq and Afghanistan: New York Univversity; 2019.

8- Ciottone GR, Biddinger PD, Darling RG, Fares S, Keim ME, Molloy MS, et al. Ciottone's disaster medicine: Elsevier Health Sciences; 2015.

9- Vernier L, Cramond V, Hoetjes M, Lenglet A, Hoare T, Malaeb $\mathrm{R}$, et al. High levels of mortality, exposure to violence and psychological distress experienced by the internally displaced population of Ein Issa camp prior to and during their displacement in Northeast Syria, November 2017. Confl Health. 2019;13:33. http://dx.doi.org/10.1186/s13031-019-0216-y www.ncbi.nlm.nih. gov/pubmed/31338121

10- Aburas R, Najeeb A, Baageel L, Mackey TK. The Syrian conflict: a case study of the challenges and acute need for medical humanitarian operations for women and children internally displaced persons. BMC Med. 2018;16(1):65. http:// dx.doi.org/10.1186/s12916-018-1041-7 www.ncbi.nlm.nih.gov/ pubmed/29747641

11- Southall D. Armed conflict women and girls who are pregnant, infants and children; a neglected public health challenge. What can health professionals do? Early Hum Dev. 2011;87(11):735-42.

\author{
تشكر و قدردانى \\ بدين وسيله از تمام محققانى كه مقالات آنها در اين مطالعه مورد \\ بررسى قرار گرفت تشكر و قدردانى مى گردد.
}

http://dx.doi.org/10.1016/j.earlhumdev.2011.08.020 www.ncbi. nlm.nih.gov/pubmed/21945358

12- Guha-Sapir D, Schlüter B, Rodriguez-Llanes JM, Lillywhite L, Hicks MH. Patterns of civilian and child deaths due to war-related violence in Syria: a comparative analysis from the Violation Documentation Center dataset, 2011-16. The Lancet Global Health. 2018;6(1):e103-e10. http://dx.doi.org/10.1016/s2214$109 x(17) 30469-2$

13- Devakumar D, Birch M, Rubenstein LS, Osrin D, Sondorp E, Wells JC. Child health in Syria: recognising the lasting effects of warfare on health. Confl Health. 2015;9:34. http://dx.doi.org/10.1186/ s13031-015-0061-6 www.ncbi.nlm.nih.gov/pubmed/26535056

14- Boyd AT, Cookson ST, Anderson M, Bilukha OO, Brennan M, Handzel T, et al. Centers for Disease Control and Prevention Public Health Response to Humanitarian Emergencies, 20072016. Emerging Infectious Diseases. 2017;23(13). http://dx.doi. org/10.3201/eid2313.170473

15- Saadi T, Abbas F, Turk T, Alkhatib M, Hanafi I, Alahdab F. Medical research in war-torn Syria: medical students' perspective. The Lancet. 2018;391(10139):2497-8. http://dx.doi.org/10.1016/ s0140-6736(18)31207-8

16- Ri S, Blair AH, Kim CJ, Haar RJ. Attacks on healthcare facilities as an indicator of violence against civilians in Syria: An exploratory analysis of open-source data. PLoS One. 2019;14(6):e0217905. http://dx.doi.org/10.1371/journal.pone.0217905 www.ncbi.nlm. nih.gov/pubmed/31181095

17- Sahloul MZ, Monla-Hassan J, Sankari A, Kherallah M, Atassi B, Badr S, et al. War is the Enemy of Health. Pulmonary, Critical Care, and Sleep Medicine in War-Torn Syria. Ann Am Thorac Soc. 2016;13(2):147-55.http://dx.doi.org/10.1513/AnnalsATS.201510661PS www.ncbi.nlm.nih.gov/pubmed/26784922

18- Trelles M, Stewart BT, Kushner AL. Attacks on civilians and hospitals must stop. The Lancet Global Health. 2016;4(5):e298-e9. http://dx.doi.org/10.1016/s2214-109x(16)00070-x

19- Kherallah M, Alahfez T, Sahloul Z, Eddin KD, Jamil G. Health care in Syria before and during the crisis. Avicenna J Med. 2012;2(3):51-3. http://dx.doi.org/10.4103/2231-0770.102275 www.ncbi.nlm.nih.gov/pubmed/23826546

20- Haar RJ, Risko CB, Singh S, Rayes D, Albaik A, Alnajar M, et al. Determining the scope of attacks on health in four governorates of Syria in 2016: Results of a field surveillance program. PLoS Med. 2018;15(4):e1002559. http://dx.doi.org/10.1371/journal. pmed.1002559 www.ncbi.nlm.nih.gov/pubmed/29689085

21- Maziak W. Syria: public health disasters in the era of no world order. 
Int J Public Health. 2018;63(3):311-2. http://dx.doi.org/10.1007/ s00038-018-1084-8 www.ncbi.nlm.nih.gov/pubmed/29464267

22- Albaroudi IN, Khodder M, Al Saadi T, Turk T, Youssef LA. Prevalence, diagnosis, and management of iron deficiency and iron deficiency anemia among Syrian children in a major outpatient center in Damascus, Syria. Avicenna J Med. 2018;8(3):92-103. http://dx.doi.org/10.4103/ajm.AJM_169_17 www.ncbi.nlm.nih. gov/pubmed/30090748

23- Mbaeyi C, Wadood ZM, Moran T, Mjourn, Ather F, Stehling-Ariza T, et al. Strategic Response to an Outbreak of Circulating VaccineDerived Poliovirus Type 2 - Syria, 2017-2018. MMWR Morb Mortal Wkly Rep. 2018;67(24):690-4. http://dx.doi.org/10.15585/ mmwr.mm6724a5 www.ncbi.nlm.nih.gov/pubmed/29927908

24- Meiqari L, Hoetjes M, Baxter L, Lenglet A. Impact of war on child health in northern Syria: the experience of Medecins Sans Frontieres. Eur J Pediatr. 2018;177(3):371-80. http:// dx.doi.org/10.1007/s00431-017-3057-y www.ncbi.nlm.nih.gov/ pubmed/29255951

25- de Lima Pereira A, Southgate R, Ahmed H, O'Connor P, Cramond $\mathrm{V}$, Lenglet A. Infectious Disease Risk and Vaccination in Northern Syria after 5 Years of Civil War: The MSF Experience. PLoS Curr. 2018;10. http://dx.doi.org/10.1371/currents.dis. bb5f22928e631dff9a80377309381feb www.ncbi.nlm.nih.gov/ pubmed/29511602

26- Perkins JD, Ajeeb M, Fadel L, Saleh G. Mental health in Syrian children with a focus on post-traumatic stress: a cross-sectional study from Syrian schools. Soc Psychiatry Psychiatr Epidemiol. 2018;53(11):1231-9. http://dx.doi.org/10.1007/s00127-018-15733 www.ncbi.nlm.nih.gov/pubmed/30083987

27- van Berlaer G, Elsafti AM, Al Safadi M, Souhil Saeed S, Buyl R, Debacker M, et al. Diagnoses, infections and injuries in Northern Syrian children during the civil war: A cross-sectional study. PLoS One. 2017;12(9):e0182770. http://dx.doi.org/10.1371/journal. pone.0182770 www.ncbi.nlm.nih.gov/pubmed/28886038

28- Sen K, Al-Faisal W, AlSaleh Y. Syria: effects of conflict and sanctions on public health. J Public Health (Oxf). 2013;35(2):1959. http://dx.doi.org/10.1093/pubmed/fds090 www.ncbi.nlm.nih. gov/pubmed/23179240

29- Gartland D, Riggs E, Muyeen S, Giallo R, Afifi TO, MacMillan $\mathrm{H}$, et al. What factors are associated with resilient outcomes in children exposed to social adversity? A systematic review. BMJ Open. 2019;9(4):e024870. http://dx.doi.org/10.1136/ bmjopen-2018-024870 www.ncbi.nlm.nih.gov/pubmed/30975671 